\title{
Intake of kale suppresses postprandial increases in plasma glucose: A randomized, double-blind, placebo-controlled, crossover study
}

\author{
SUMIO KONDO $^{1}$, ASAHI SUZUKI ${ }^{2}$, MIHOKO KUROKAWA $^{2}$ and KEIJI HASUMI ${ }^{3}$ \\ ${ }^{1}$ Medical Corporation Kenshokai, Fukushima Healthcare Center, Osaka 530-0038; ${ }^{2}$ Q'sai Co., Ltd., Fukuoka 810-8606; \\ ${ }^{3}$ Department of Applied Biological Science, Tokyo Noko University, Fuchu-Si, Tokyo 183-8509, Japan
}

Received May 25, 2016; Accepted August 31, 2016

DOI: $10.3892 /$ br.2016.767

\begin{abstract}
Kale (Brassica oleracea var. acephala), a vegetable in the family Brassicaceae, has beneficial effects on health, including hypoglycemic effects. In our previous study with a limited number of subjects, intake of kale-containing food at a dose of $14 \mathrm{~g}$ decreased postprandial plasma glucose levels. In the present study, the effective dose of kale-containing food was investigated in a randomized, double-blind, placebo-controlled, crossover trial. The trial was conducted on 42 Japanese subjects aged 21-64 years with fasting plasma glucose levels of $\leq 125 \mathrm{mg} / \mathrm{dl}$ and 30 -min postprandial plasma glucose levels of $140-187 \mathrm{mg} / \mathrm{dl}$. The subjects consumed placebo or kale-containing food [7 or $14 \mathrm{~g}$; low-dose (active-L) or high-dose (active-H) kale, respectively] together with a high-carbohydrate meal. At 30-120 min after the test meal intake, the plasma levels of glucose and insulin were determined. The postprandial plasma glucose levels in subjects with intake of active-L or active-H were significantly lower than those in subjects with intake of placebo, with the maximum plasma concentration $\left(\mathrm{C}_{\max } ; 163 \pm 24 \mathrm{mg} / \mathrm{dl}\right.$ for active- $\mathrm{L}$ and $162 \pm 23 \mathrm{mg} / \mathrm{dl}$ for active-H compared with $176 \pm 26 \mathrm{mg} / \mathrm{dl}$ for placebo [values presented as means \pm standard deviation (SD); $\mathrm{P}<0.01]$. The area under the plasma glucose concentration-time curve for $0-2 \mathrm{~h}\left(\mathrm{AUC}_{0-2 \mathrm{~h}}\right)$ values (means $\pm \mathrm{SD}$ ) were significantly lower for active-L $(268 \pm 43 \mathrm{mg} / \mathrm{h} / \mathrm{dl})$ and active-H $(266 \pm 42 \mathrm{mg} / \mathrm{h} / \mathrm{dl})$ than for the placebo $(284 \pm 43 \mathrm{mg} / \mathrm{h} / \mathrm{dl}$; $\mathrm{P}<0.05)$. No significant differences were identified in the postprandial plasma insulin levels between the three conditions. No adverse events associated with intake of either dose of kale were observed. Our findings suggest that intake of kale suppresses postprandial increases in plasma glucose levels at a single dose of $7 \mathrm{~g}$, and that a dose as high as $14 \mathrm{~g}$ is safe.
\end{abstract}

Correspondence to: Ms. Asahi Suzuki, Q'sai Co., Ltd., 1-7-16 Kusagae, Chuo-ku, Fukuoka 810-8606, Japan

E-mail: a_suzuki@kyusai.co.jp

Key words: kale, postprandial hyperglycemia, plasma glucose, anti-diabetic, clinical study

\section{Introduction}

The incidence of diabetes is increasing worldwide, and its prevalence reached 415 million people in 2015 (1). Up to 91\% of adults with diabetes mellitus are diagnosed with type 2 diabetes in high-income countries. There is a long asymptomatic phase (the prediabetic phase) during the progression of type 2 diabetes. Significant proportions of patients may develop retinopathy, cardiovascular disease, neuropathy, and nephropathy in the prediabetic phase $(2,3)$. Lifestyle modification or pharmacotherapy is beneficial for diabetes prevention in prediabetic individuals $(2,4-7)$. Impaired fasting glucose (where the fasting plasma glucose level does not meet the criteria for diabetes, but is above the normal level) is an intermediate state of hyperglycemia (8) and adopted as a measure for identifying high-risk populations for type 2 diabetes (4). In addition, accumulating evidence suggests that postprandial hyperglycemia participates in the development of impaired fasting glucose (9) and is an independent risk factor for atherosclerosis, with a greater effect than fasting hyperglycemia (10).

Recent investigations have suggested that vegetarian diets are effective for glycemic control in diabetes (11-13). Regarding the suppression of postprandial hyperglycemia, the efficacy of indigestible dextrin or wheat albumin has been reported $(14,15)$. Our previous study suggested that intake of kale (Brassica oleracea var. acephala) is effective in reducing postprandial plasma glucose (16). In the present study, we investigated the effective dose of kale-containing food in a randomized, double-blind, placebo-controlled, crossover trial involving subjects with moderately high postprandial plasma glucose levels.

\section{Materials and methods}

Food samples. The following food samples were produced by Q'sai Co., Ltd. (Fukuoka, Japan): Placebo; low-dose kale (7 g kale-containing food; active-L); and high-dose kale (14 g kale-containing food; active-H). The ingredients of the food samples are presented in Table I. At the measurement times (test periods I, II and III, in which each experimental procedure was performed in one day), the subjects consumed one of the food samples together with a high-carbohydrate meal 
(rice with chicken and eggs; $575 \mathrm{kcal}$ energy, $18.7 \mathrm{~g}$ protein, $3.2 \mathrm{~g}$ fat, $115.6 \mathrm{~g}$ carbohydrate, and 1,243 $\mathrm{mg}$ sodium in a total meal of $510 \mathrm{~g}$ ). The meal duration time was set at $10 \mathrm{~min}$. The dose of kale was defined based on our previous clinical trial of its effect on postprandial plasma glucose levels (16). In that randomized, double-blind, placebo-controlled, crossover study, intake of kale-containing food at a dose of $14 \mathrm{~g}$ significantly decreased postprandial plasma glucose levels. To investigate the appropriate effective dose, the doses were set at 7 and $14 \mathrm{~g}$ in the present study.

Study design. A randomized, double-blind, placebo-controlled, crossover study was conducted with the aid of a fund from Q'sai Co., Ltd. at two centers (Kenshokai Fukushima Health Care Center, Osaka, Japan; and Go Clinic, Osaka, Japan) under the supervision of the principal investigator (Dr Sumio Kondo; Kenshokai Fukushima Health Care Center). The study was conducted from April to July 2015. The study conformed to the principles of the Declaration of Helsinki and was approved by the institutional review board of the incorporated medical institution (Aiseikai Aisei Hospital Ueno Clinic, Tokyo, Japan) on the basis of ethical issues, the protocol, and information on the food samples.

The subjects were recruited in April 2015. The details of the study were disclosed to the subjects before the start of the study, and informed consent was obtained from all subjects. The inclusion criteria were as follows: i) Male or female aged between 20 and 64 years; ii) fasting plasma glucose level of $\leq 125 \mathrm{mg} / \mathrm{dl}$ at the pretrial test; and iii) postprandial plasma glucose level of 140-199 mg/dl at $30 \mathrm{~min}$ after intake of the high-carbohydrate meal at the pretrial test. The exclusion criteria were as follows: i) Those habitually taking green vegetable juice three times or more per week; ii) those taking health foods or medicines that may affect sugar metabolism; iii) those suffering from any disease or with a case history of a serious disease that required medication; iv) those suffering from serious diseases, such as diabetes mellitus or failure of the liver, kidney, or heart, or with a case history of such diseases; v) those taking warfarin, a vitamin K-dependent anticoagulant that inhibits synthesis of coagulation factors; vi) those who may be liable to allergy in response to kale or the high-carbohydrate meal containing rice, chicken, and egg; vii) those participating in any other clinical trial within 1 month or planning to participate in such trials after providing informed consent to join the present study; viii) those planning to get pregnant or nurse a baby during the study; ix) those judged inappropriate as participants from answers to the lifestyle questionnaire; and $\mathrm{x}$ ) those judged inappropriate as participants from the view of the principal investigator. The 42 included subjects were 23 men and 19 women aged $44.7 \pm 11.1$ years. The subjects were assigned to group $X(n=14)$, group $Y(n=14)$, and group $Z(n=14)$ based on random number tables. The allocation was conducted by Yoshihisa Kibune (TTC Co., Ltd., Tokyo, Japan) and concealed from the subjects, the investigators, and the researchers who recruited and assessed the subjects. In the three test periods (periods I, II and III), the subjects in the three groups were assigned to consume the food samples as shown in Fig. 1.

During the trial, the following requests were made to the participants: i) Not to change their lifestyle, including diet, alcohol drinking, and sleep patterns; ii) to avoid over-exercising,
Table I. Compositions of the food samples.

\begin{tabular}{lccc}
\hline Ingredient (per 100 g) & Placebo & Active-L & Active-H \\
\hline Energy (kcal) & 377 & 339 & 299 \\
Protein (g) & 0.2 & 8.3 & 16.6 \\
Fat (g) & 0.3 & 2.6 & 4.7 \\
Carbohydrate (g) & 93.4 & 79.7 & 66.0 \\
Sodium (mg) & 43.5 & 164 & 283 \\
\hline
\end{tabular}

Active-L, low-dose kale; active-H, high-dose kale.

abstemious eating, or overeating; iii) not to change their exercise habits; iv) not to take health foods or supplements; v) to log their lifestyle each day; vi) to go to bed by 12:00 a.m. on the day before the tests; vii) to avoid drinking alcohol for 2 days before the test; viii) to avoid consuming any meals after dinner on the day before the test and to continue abstaining from food until the test; ix) not to consume a high-fat meal the day before the test; $x$ ) to eat dinner at the usual time; $x i)$ not to drastically change the dietary composition of their dinner on the day before the test; xii) to avoid heavy exercise on the day before the test and the day of the test; and xiii) not to consume any meal other than that provided for the test on the day of the test.

In each of the test periods I, II or III, the participants consumed one of the food samples together with the high-carbohydrate meal (Fig. 1). The plasma glucose and insulin levels were measured before (preprandial) and at 30, 60, 90 and 120 min after the meal. Each participant logged their lifestyle during the 3 days before the test. There were 1-week washout periods between test periods I and II, and between test periods II and III.

The primary outcome measure was plasma glucose level at 30 min following consumption of the high-carbohydrate meal. The secondary outcome measures were as follows: Plasma glucose area under the blood concentration-time curve (AUC) for the plasma glucose level determined using values obtained for up to $2 \mathrm{~h}$ following the high-carbohydrate meal $\left(\mathrm{AUC}_{0-2 \mathrm{~h}}\right)$; plasma glucose maximum plasma concentration $\left(\mathrm{C}_{\max }\right)$; fasting plasma glucose level; plasma glucose levels at 60, 90 and 120 min after meal consumption; fasting plasma insulin level; and plasma insulin levels at 30,60,90 and $120 \mathrm{~min}$ after meal consumption.

Measurements of glucose and insulin plasma levels. The following measurements were performed according to the standard laboratory protocol of LSI Medience Corporation (Tokyo, Japan). Plasma glucose was determined by glucose oxidase-electrochemical assay using a GA081ll automated glucose analyzer (A\&T Corporation, Yokohama, Japan). Plasma insulin was determined by chemiluminescence immunoassay using an ARCHITECT i2000 analyzer (Abbott Japan, Tokyo, Japan). The AUC for the plasma glucose level was determined using values obtained for up to $2 \mathrm{~h}$ following the high-carbohydrate meal ( $\left.\mathrm{AUC}_{0-2 \mathrm{~h}}\right)$.

Additional surveys and testing. Further surveys and testing were performed on the indicated occasions as follows: Lifestyle 


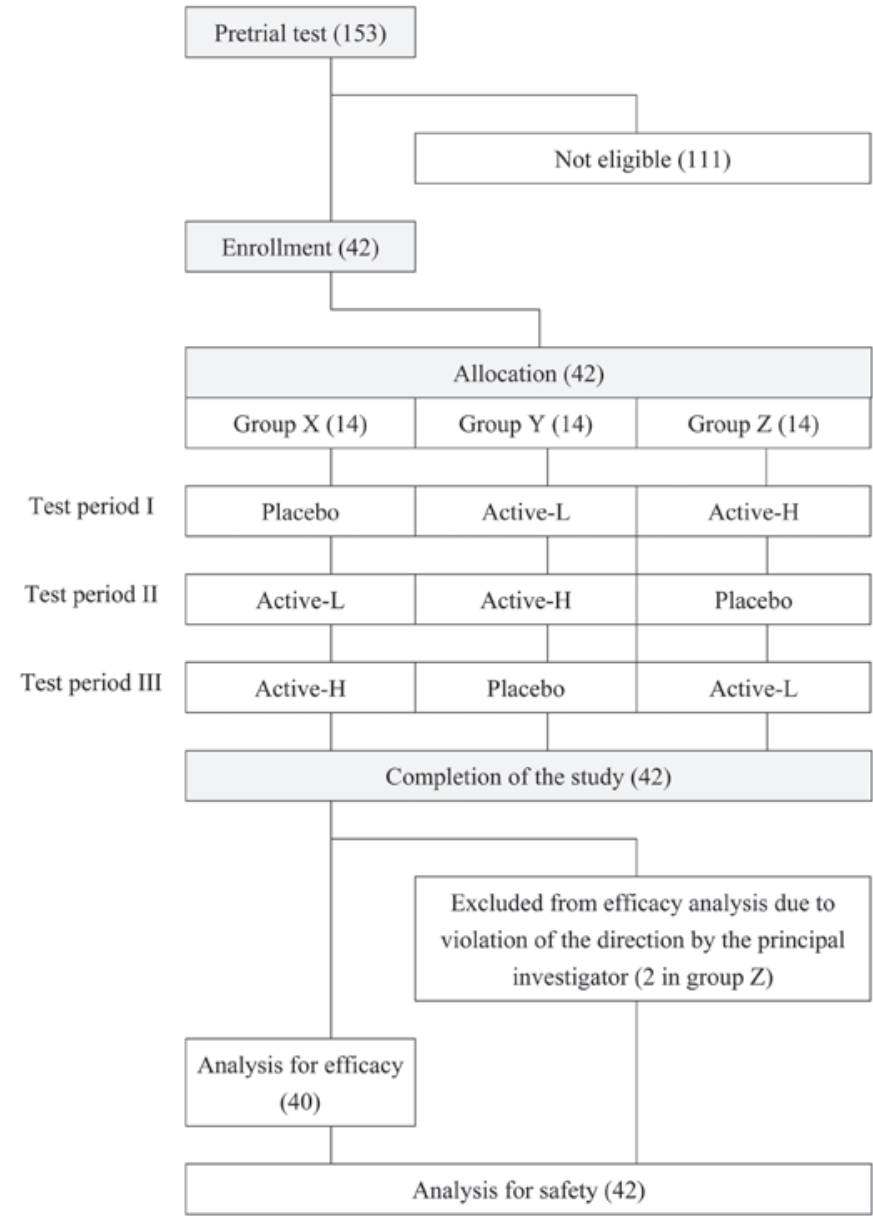

Figure 1. Flow diagram of the study. Numbers in parentheses denote the number of subjects. The inclusion of the subjects was judged by the principal investigator.

questionnaire, physical examination and laboratory examination at pretrial testing; a medical interview, and somatometry at pretrial testing and test periods I, II and III.

Measurement of viscosity. An artificial digest consisting of $2 \%(\mathrm{w} / \mathrm{v})$ methylcellulose and $5 \%(\mathrm{w} / \mathrm{v})$ glucose was added to the powdered kale $(1-4.8 \%$; w/v) or kale-derived dietary fiber $(0.5-1.2 \%$; w/v), and viscosity of the resulting mixture was measured three times using an FCV-100 ultrasonic viscosity meter (Fuji Ultrasonic Engineering, Hamamatsu, Japan). Values are presented as units of $\mathrm{mPa} \cdot \mathrm{s}$.

Statistical analysis. All of the measured values are expressed as means \pm standard deviation. The statistical methods used for analysis were as follows: Analysis of variance (ANOVA) for subject background data; $\chi^{2}$ test for subject number; ANOVA for comparisons between groups $\mathrm{X}, \mathrm{Y}$ and $\mathrm{Z}$ and for inter-individual, -period, and -food sample comparisons; Tukey's test for efficacy of the food samples and viscosity results. $\mathrm{P}<0.05$ was considered to indicate a statistically significant difference.

\section{Results}

Subjects. Forty-two subjects were enrolled and randomly allocated to the three groups (groups $\mathrm{X}, \mathrm{Y}$ and $\mathrm{Z}$ ). The subjects consumed one of the food samples, which were comprised of a placebo, active-L, or active-H, at each of the three test periods, as depicted in Fig. 1. All of the participants completed the study, but two subjects in group $\mathrm{Z}$ violated the directions from the principal investigator. These two subjects were excluded from the analysis of efficacy, but included in the analysis for safety (Fig. 1). The background data for the three groups are presented in Table II. ANOVA revealed no significant inter-group variation in the background data (Table II).

Effects on postprandial plasma glucose levels. As shown in Table III, no significant inter-period differences in the levels of fasting plasma glucose, $\mathrm{AUC}_{0-2 \mathrm{~h}}$, or $\mathrm{C}_{\max }$ were identified. Furthermore, no significant inter-food sample differences were observed in the levels of fasting plasma glucose. Thus, no obvious bias that hampered analyses of $\mathrm{AUC}_{0-2 \mathrm{~h}}$ or $\mathrm{C}_{\max }$ was noted, therefore usual statistical methods for the analysis of efficacy were employed. However, there were significant inter-period differences in the levels of plasma glucose at 30 and $120 \mathrm{~min}$ (Table III); therefore, these data were excluded from the statistical analysis of efficacy.

Fig. 2A shows the time courses of the changes in plasma glucose following consumption of the high-carbohydrate test meal. The level increased transiently following consumption of the test meal, with a peak at $\sim 30-60 \mathrm{~min}$, when the subjects consumed the placebo. The increase was significantly smaller when the subjects consumed the kale-containing food (active- $\mathrm{L}$ or active- $\mathrm{H}$ ) compared with the placebo according to Tukey's test $(\mathrm{P}<0.01$ at $60 \mathrm{~min})$. No significant differences were identified between the values obtained with active-L and active- $\mathrm{H}$. The $\mathrm{C}_{\max }$ values $(\mathrm{mg} / \mathrm{dl})$ were calculated to be $176.0 \pm 25.6$ for placebo, 163.2 \pm 24.2 for active- $\mathrm{L}(\mathrm{P}<0.01$ vs. placebo), and $162.0 \pm 22.9$ for active-H ( $\mathrm{P}<0.01$ vs. placebo; Fig. 2B). The $\mathrm{AUC}_{0-2 \mathrm{~h}}$ values $(\mathrm{mg} / \mathrm{h} / \mathrm{dl})$ were $284.2 \pm 43.0$ for placebo, 268.4 \pm 42.6 for active- $\mathrm{L}(\mathrm{P}<0.05$ vs. placebo), and $266.3 \pm 41.9$ for active-H ( $\mathrm{P}<0.05$ vs. placebo; Fig. $2 \mathrm{C})$.

Effects on postprandial plasma insulin levels. The data are summarized in Table IV. The plasma level of insulin increased transiently after the test meal intake, with a peak at $~ 30$ min, when the subjects consumed the placebo. When the subjects consumed the kale-containing food (active-L or active-H), the increases in plasma insulin level were moderate, and the differences were not significant.

Effects of an artificial digest on viscosity. The addition of powdered kale, the active ingredient of the test food, at $1-4.8 \%(\mathrm{w} / \mathrm{v})$ resulted in a dose-dependent increase in viscosity of the mixture (Fig. 3). Furthermore, kale-derived dietary fiber exerted a potent effect when added at $0.5-1.2 \%$ $(\mathrm{w} / \mathrm{v})$. The effect exerted by kale-derived dietary fiber at $0.5 \%$ $(\mathrm{w} / \mathrm{v})$ was comparable to that exerted by kale powder at $4.8 \%$ (w/v; Fig. 3).

Adverse events. There were no adverse events considered to be caused by consumption of the kale-containing food, based on the judgment of the principal investigator after examining data for physical measurements, blood biochemistry, hematology and urinalysis, as well as medical interview. 
Table II. Background characteristics of the subjects in groups $\mathrm{X}, \mathrm{Y}$ and $\mathrm{Z}$.

\begin{tabular}{|c|c|c|}
\hline Parameter & Value & P-value \\
\hline Subjects (m/f) & & $0.672^{\mathrm{a}}$ \\
\hline $\mathrm{X}$ & $7 / 7$ & \\
\hline $\mathrm{Y}$ & $8 / 6$ & \\
\hline $\mathrm{Z}$ & $8 / 4$ & \\
\hline Total & $23 / 17$ & \\
\hline Age (years) & & $0.345^{\mathrm{b}}$ \\
\hline $\mathrm{X}$ & $46.9 \pm 9.9$ & \\
\hline $\mathrm{Y}$ & $45.0 \pm 10.6$ & \\
\hline $\mathrm{Z}$ & $40.5 \pm 13.0$ & \\
\hline Total & $44.3 \pm 11.2$ & \\
\hline Height (cm) & & $0.510^{\mathrm{b}}$ \\
\hline $\mathrm{X}$ & $167.86 \pm 9.45$ & \\
\hline $\mathrm{Y}$ & $164.45 \pm 10.09$ & \\
\hline $\mathrm{Z}$ & $168.14 \pm 7.40$ & \\
\hline Total & $166.75 \pm 9.06$ & \\
\hline Body weight (kg) & & $0.629^{\mathrm{b}}$ \\
\hline $\mathrm{X}$ & $64.86 \pm 12.98$ & \\
\hline $\mathrm{Y}$ & $61.51 \pm 11.83$ & \\
\hline $\mathrm{Z}$ & $65.85 \pm 11.46$ & \\
\hline Total & $63.99 \pm 11.97$ & \\
\hline Body mass index $\left(\mathrm{kg} / \mathrm{m}^{2}\right)$ & & $0.908^{\mathrm{b}}$ \\
\hline$X$ & $22.87 \pm 3.16$ & \\
\hline $\mathrm{Y}$ & $22.69 \pm 3.43$ & \\
\hline $\mathrm{Z}$ & $23.27 \pm 3.70$ & \\
\hline Total & $22.92 \pm 3.34$ & \\
\hline $\begin{array}{l}\text { Fasting plasma } \\
\text { glucose level (mg/dl) }\end{array}$ & & $0.442^{\mathrm{b}}$ \\
\hline $\mathrm{X}$ & $97.3 \pm 8.6$ & \\
\hline $\mathrm{Y}$ & $94.4 \pm 6.5$ & \\
\hline $\mathrm{Z}$ & $98.4 \pm 9.9$ & \\
\hline Total & $96.6 \pm 8.3$ & \\
\hline $\begin{array}{l}\text { Plasma glucose level } 30 \mathrm{~min} \\
\text { after the meal intake }(\mathrm{mg} / \mathrm{dl})\end{array}$ & & $0.806^{\mathrm{b}}$ \\
\hline $\mathrm{X}$ & $160.8 \pm 14.3$ & \\
\hline $\mathrm{Y}$ & $159.9 \pm 14.7$ & \\
\hline $\mathrm{Z}$ & $163.3 \pm 10.4$ & \\
\hline Total & $161.2 \pm 13.1$ & \\
\hline Plasma glucose $\mathrm{AUC}_{0-2 \mathrm{~h}}(\mathrm{mg} / \mathrm{h} / \mathrm{dl})$ & & $0.751^{\mathrm{b}}$ \\
\hline $\mathrm{X}$ & $284.1 \pm 24.4$ & \\
\hline $\mathrm{Y}$ & $276.3 \pm 37.6$ & \\
\hline $\mathrm{Z}$ & $288.0 \pm 55.0$ & \\
\hline Total & $282.5 \pm 39.3$ & \\
\hline Plasma glucose $\mathrm{C}_{\max }(\mathrm{mg} / \mathrm{dl})$ & & $0.483^{\mathrm{b}}$ \\
\hline $\mathrm{X}$ & $168.6 \pm 15.6$ & \\
\hline $\mathrm{Y}$ & $165.6 \pm 22.5$ & \\
\hline $\mathrm{Z}$ & $176.9 \pm 33.0$ & \\
\hline Total & $170.1 \pm 24.1$ & \\
\hline
\end{tabular}

Data are presented as means \pm standard deviation. ${ }^{\mathrm{a}} \chi^{2}$ test; ${ }^{\mathrm{b}}$ analysis of variance. $\mathrm{AUC}_{0-2 \mathrm{~h}}$, area under the concentration-time curve for $0-2 \mathrm{~h}$; $\mathrm{C}_{\max }$, maximum plasma concentration.
Table III. Analysis of variance for changes in plasma glucose levels, as well as $\mathrm{AUC}_{0-2 \mathrm{~h}}$ and $\mathrm{C}_{\max }$ values following consumption of the high-carbohydrate meal.

\begin{tabular}{|c|c|c|c|}
\hline \multirow[b]{2}{*}{ Item } & \multicolumn{2}{|c|}{ P-value } & \multirow{2}{*}{$\begin{array}{r}\text { Inter-foo } \\
\text { sample }\end{array}$} \\
\hline & Inter-individual & Inter-period & \\
\hline \multicolumn{4}{|l|}{$\begin{array}{l}\text { Plasma glucose } \\
\text { level }\end{array}$} \\
\hline Fasting & $<0.001$ & 0.962 & 0.472 \\
\hline $\begin{array}{l}30 \text { min after } \\
\text { meal intake }\end{array}$ & $<0.001$ & 0.048 & $<0.001$ \\
\hline $\begin{array}{l}60 \text { min after test } \\
\text { meal intake }\end{array}$ & $<0.001$ & 0.287 & $<0.001$ \\
\hline $\begin{array}{l}90 \text { min after test } \\
\text { meal intake }\end{array}$ & $<0.001$ & 0.177 & 0.308 \\
\hline $\begin{array}{l}120 \text { min after test } \\
\text { meal intake }\end{array}$ & $<0.001$ & 0.019 & 0.396 \\
\hline $\mathrm{AUC}_{0-2 \mathrm{~h}}$ & $<0.001$ & 0.252 & 0.008 \\
\hline $\mathrm{C}_{\max }$ & $<0.001$ & 0.178 & $<0.001$ \\
\hline
\end{tabular}

P-values were derived by analysis of variance. $\mathrm{AUC}_{0-2 \mathrm{~h}}$, area under the plasma glucose concentration-time curve for $0-2 \mathrm{~h} ; \mathrm{C}_{\max }$, maximum plasma glucose concentration.

\section{Discussion}

Postprandial hyperglycemia causes impaired fasting glucose, which is a risk factor of type 2 diabetes $(4,9)$. Lifestyle modification, particularly through diet, is an attractive means of controlling hyperglycemia. Kale has good nutritive value, antioxidant activity, and health-benefits (17-19), and is widely consumed in Western countries. In Japan, drinks prepared from kale-containing green powder are consumed to supplement vegetable intake or promote health. As part of our survey of health-promoting effects of kale-containing green drinks, its effect on postprandial hyperglycermia were investigated. The preliminary results suggested that intake of kale reduced postprandial plasma glucose levels (16).

The aim of the present study was to investigate the effective dose of kale for postprandial plasma glucose levels in humans. The subjects involved in this randomized, double-blind, placebo-controlled, crossover trial exhibited slightly elevated postprandial plasma glucose levels. They consumed placebo or kale-containing food once with a meal, and their plasma glucose levels were measured for up to $2 \mathrm{~h}$ after the meal. As the aim of the study was to investigate the effective dose of the kale-containing food, the effects of a dose of $7 \mathrm{~g}$ kale were compared with those of a dose of $14 \mathrm{~g}$ kale, as the efficacy of kale at $14 \mathrm{~g}$ was demonstrated in our previous study (16). In the present study, it was found that kale at a dose of $7 \mathrm{~g}$ was as effective as kale at a dose of $14 \mathrm{~g}$ in suppressing postprandial increases in plasma glucose levels. Thus, the impact of kale on postprandial hyperglycemia was demonstrated effectively, and the intake of kale-containing food at a dose of $7 \mathrm{~g}$ was identified to be sufficient to exert its effect. 
Table IV. Effects of kale intake on the levels of postprandial plasma insulin.

\begin{tabular}{lccccc}
\hline & \multicolumn{5}{c}{ Plasma insulin level $(\mu \mathrm{U} / \mathrm{ml})$} \\
\cline { 2 - 5 } Test sample & Preprandial & $30 \mathrm{~min}$ & $60 \mathrm{~min}$ & $90 \mathrm{~min}$ & $120 \mathrm{~min}$ \\
\hline Placebo & $4.46 \pm 2.39$ & $48.61 \pm 31.29$ & $59.41 \pm 35.98$ & $46.53 \pm 28.91$ & $45.08 \pm 33.40$ \\
Active-L & $4.38 \pm 2.07^{\mathrm{a}}$ & $44.70 \pm 30.58$ & $54.27 \pm 34.15$ & $44.08 \pm 30.31$ & $39.50 \pm 27.86$ \\
Active-H & $4.10 \pm 2.28$ & $45.40 \pm 29.31$ & $52.15 \pm 30.71$ & $41.13 \pm 23.49$ & $36.46 \pm 21.49^{\mathrm{a}}$ \\
\hline
\end{tabular}

Data are presented as means \pm standard deviation ( $n=40$, except for the values indicated by ${ }^{\text {a }}$, where $n=39$ owing to a lack of data). No significant differences were identified between any groups by Tukey's test. Active-L, low dose kale; Active-H, high dose kale.

A

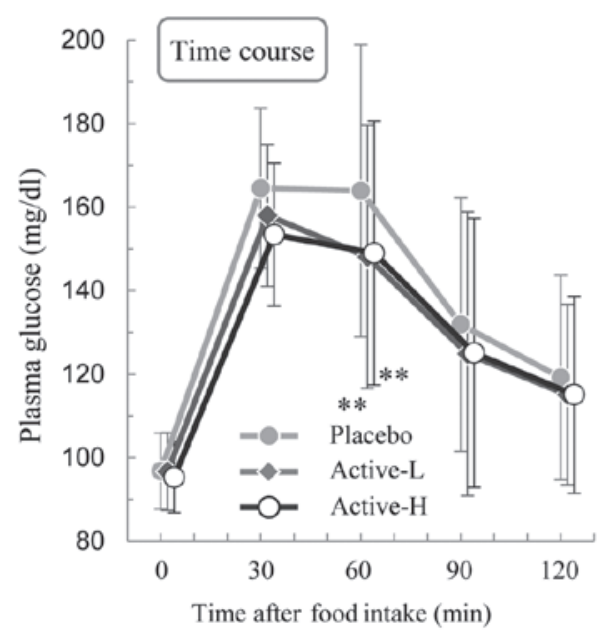

B

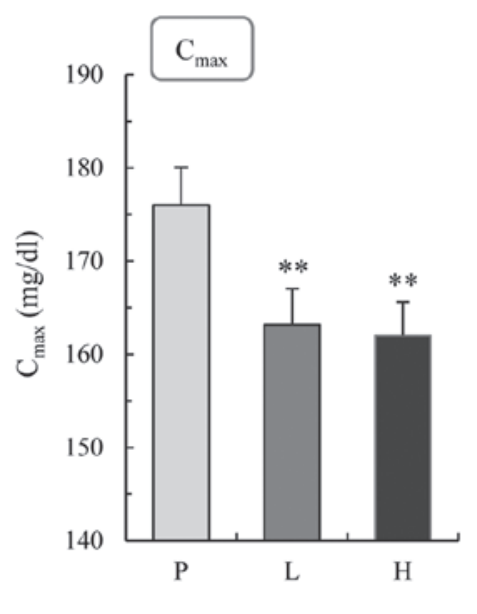

$\mathrm{C}$

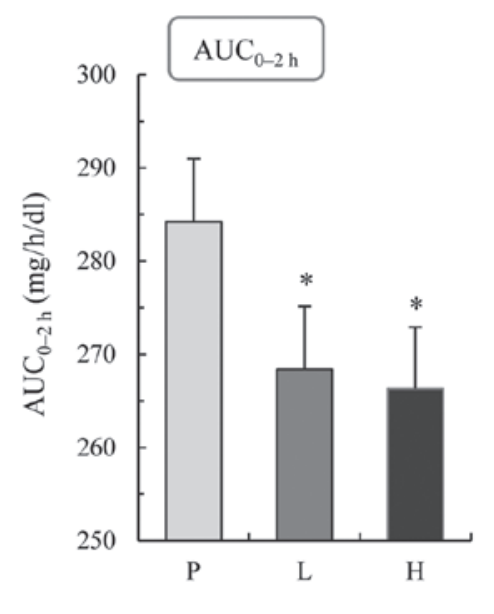

Figure 2. Effects of kale on postprandial plasma glucose levels. (A) Time courses of the changes in plasma glucose levels following consumption of the high-carbohydrate meal together with placebo $(\mathrm{P})$, active-L $(\mathrm{L})$ or active-H $(\mathrm{H}) .(\mathrm{B}) \mathrm{C}_{\max }$ and $(\mathrm{C}) \mathrm{AUC} \mathrm{C}_{0-2 \mathrm{~h}}$ values for plasma glucose. ${ }^{*} \mathrm{P}<0.05{ }^{* *} \mathrm{P}<0.01$ vs. placebo (Tukey's test). Data are presented as means \pm standard deviation $(n=40)$. Active-L, low-dose kale; active-H, high-dose kale; $\mathrm{C}_{\max }, \mathrm{maximum}$ plasma glucose concentration; $\mathrm{AUC}_{0-2 \mathrm{~h}}$, area under the plasma glucose concentration-time curve for 0-2 $\mathrm{h}$.

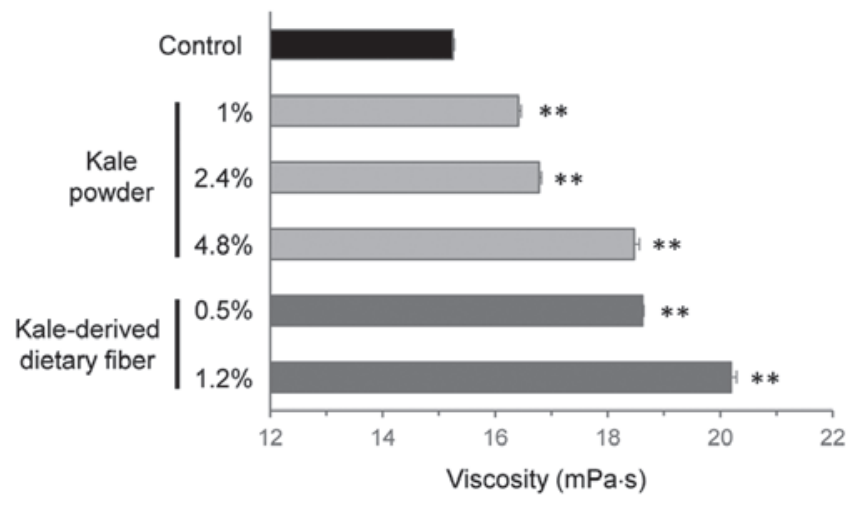

Figure 3. Effects of kale and kale-derived dietary fiber on viscosity of an artificial digest. Kale powder or kale-derived dietary fiber was added at the indicated concentration to an artificial digest, and viscosity of the resulting mixture was determined three times using an ultrasonic viscosity meter. ${ }^{* *} \mathrm{P}<0.01$ vs. control (Tukey's test).

Kale contains significant quantities of dietary fibers $(18,20)$, which prevent postprandial elevation of plasma glucose (21). A possible underlying mechanism responsible for this effect of plasma glucose is an increase in intestinal viscosity, which delays the absorption of nutrients $(22,23)$. The kale-containing food used in the current clinical study significantly increased viscosity at concentrations of $>1 \%$ during in vitro experiments. In addition, the dietary fiber fraction of the kale-containing food was effective for increasing viscosity at concentrations as low as $0.5 \%$ (Fig. 3). Thus, it is hypothesized that an increase in viscosity in the gut may have contributed to the effect observed in the current study.

The present finding that kale consumption ameliorates postprandial hyperlipidemia may contribute to developing the concept of dietary control of hyperglycemia. The present study, however, was performed with limited numbers of subjects whose 30-min postprandial plasma glucose levels were $140-187 \mathrm{mg} / \mathrm{dl}$. For the American Diabetes Association, the postprandial glycemic threshold value has been set at $180 \mathrm{mg} / \mathrm{dl}$ (24). Therefore, further investigations are required to examine the efficacy of kale consumption in subjects with more severe postprandial hyperglycemia.

\section{Acknowledgements}

Asahi Suzuki and Mihoko Kurokawa are employees of Q'sai Co., Ltd., which provided the research expenses to TTC Co., 
Ltd. Asahi Suzuki and Mihoko Kurokawa were not involved in the interpretation of the results, and not influenced the outcomes at any stage of the clinical trial.

\section{References}

1. International Diabetes Federation (IDF): IDF Diabetes Atlas. 7th edition. IDF, Brussels, 2015.

2. Tabák AG, Herder C, Rathmann W, Brunner EJ and Kivimäki M: Prediabetes: A high-risk state for diabetes development Lancet 379: 2279-2290, 2012.

3. Grundy SM: Pre-diabetes, metabolic syndrome, and cardiovascular risk. J Am Coll Cardiol 59: 635-643, 2012.

4. Knowler WC, Fowler SE, Hamman RF, Christophi CA, Hoffman HJ, Brenneman AT, Brown-Friday JO, Goldberg R, Venditti E and Nathan DM; Diabetes Prevention Program Research Group: 10-year follow-up of diabetes incidence and weight loss in the Diabetes Prevention Program Outcomes Study. Lancet 374: 1677-1686, 2009.

5. Gerstein HC, Yusuf S, Bosch J, Pogue J, Sheridan P, Dinccag N, Hanefeld M, Hoogwerf B, Laakso M, Mohan V, et al; DREAM (Diabetes REduction Assessment with ramipril and rosiglitazone Medication) Trial Investigators: Effect of rosiglitazone on the frequency of diabetes in patients with impaired glucose tolerance or impaired fasting glucose: A randomised controlled trial Lancet 368: 1096-1105, 2006.

6. Knowler WC, Barrett-Connor E, Fowler SE, Hamman RF, Lachin JM, Walker EA and Nathan DM; Diabetes Prevention Program Research Group: Reduction in the incidence of type 2 diabetes with lifestyle intervention or metformin. N Engl J Med 346: 393-403, 2002.

7. Ramachandran A, Snehalatha C, Mary S, Mukesh B, Bhaskar AD and Vijay V; Indian Diabetes Prevention Programme (IDPP): The Indian Diabetes Prevention Programme shows that lifestyle modification and metformin prevent type 2 diabetes in Asian Indian subjects with impaired glucose tolerance (IDPP-1). Diabetologia 49: 289-297, 2006.

8. Heianza Y, Hara S, Arase Y, Saito K, Fujiwara K, Tsuji H, Kodama S, Hsieh SD, Mori Y, Shimano H, et al: HbAlc 5·7-6.4\% and impaired fasting plasma glucose for diagnosis of prediabetes and risk of progression to diabetes in Japan (TOPICS 3): A longitudinal cohort study. Lancet 378: 147-155, 2011.

9. Tabák AG, Jokela M, Akbaraly TN, Brunner EJ, Kivimäki M and Witte DR: Trajectories of glycaemia, insulin sensitivity, and insulin secretion before diagnosis of type 2 diabetes: An analysis from the Whitehall II study. Lancet 373: 2215-2221, 2009.

10. Node K and Inoue T: Postprandial hyperglycemia as an etiological factor in vascular failure. Cardiovasc Diabetol 8: 23, 2009.
11. Trapp C and Levin S: Preparing to prescribe plant-based diets for diabetes prevention and treatment. Diabetes Spectrum 25: 38-44, 2012.

12. Orlich MJ and Fraser GE: Vegetarian diets in the Adventist Health Study 2: A review of initial published findings. Am J Clin Nutr 100 (Suppl 1): 353S-358S, 2014.

13. Yokoyama Y, Barnard ND, Levin SM and Watanabe M: Vegetarian diets and glycemic control in diabetes: A systematic review and meta-analysis. Cardiovasc Diagn Ther 4: 373-382, 2014.

14. Hobden MR, Guérin-Deremaux L, Rowland I, Gibson GR and Kennedy OB: Potential anti-obesogenic properties of non-digestible carbohydrates: Specific focus on resistant dextrin. Proc Nutr Soc 74: 258-267, 2015.

15. Murayama Y, Mochizuki K, Shimada M, Fujimoto S, Nukui K, Shibata K and Goda T: Dietary supplementation with alpha-amylase inhibitor wheat albumin to high-fat diet-induced insulin-resistant rats is associated with increased expression of genes related to fatty acid synthesis in adipose tissue. J Agric Food Chem 57: 9332-9338, 2009.

16. Korenori Y, Suzuki A, Kurokawa M and Saito J: Beneficial effects of dietary intake of food containing kale (Brassica oleracea var. acephala) on postprandial blood glucose in humans. A randomized, placebo-controlled, double-blind, crossover study. Jpn Pharmacol Ther 43: 1157-1163, 2015.

17. Kim SY: Comparison of nutritional compositions and antioxidant activities of building blocks in shinseoncho and kale green vegetable juices. Prev Nutr Food Sci 17: 269-273, 2012.

18. Sikora E and Bodziarczyk I: Composition and antioxidant activity of kale (Brassica oleracea L. var. acephala) raw and cooked. Acta Sci Pol Technol Aliment 11: 239-248, 2012.

19. Ismail A, Marjan ZM and Foong CW: Total antioxidant activity and phenolic content in selected vegetables. Food Chem 87: 581-586, 2004.

20. Migliozzi M, Thavarajah D, Thavarajah P and Smith P: Lentil and kale: Complementary nutrient-rich whole food sources to combat micronutrient and calorie malnutrition. Nutrients 7 : 9285-9298, 2015.

21. Lattimer JM and Haub MD: Effects of dietary fiber and its components on metabolic health. Nutrients 2: 1266-1289, 2010.

22. Lightowler HJ and Henry CJ: Glycemic response of mashed potato containing high-viscocity hydroxypropylmethylcellulose. Nutr Res 29: 551-557, 2009.

23. Maki KC, Davidson MH, Witchger MS, Dicklin MR and Subbaiah PV: Effects of high-fiber oat and wheat cereals on postprandial glucose and lipid responses in healthy men. Int J Vitam Nutr Res 77: 347-356, 2007.

24. American Diabetes Association: 5. Glycemic Targets. Diabetes Care 39 (Suppl 1): S39-S46, 2016. 